\title{
Evaluation of long-term sagittal lip changes using Burstone line: Pilot Study
}

\author{
Sathekge Rachel ${ }^{1}$; Lesar Colin ${ }^{2}$ \\ 1. Military Hospital, Department of Orthodontics; previously University of Witwatersrand Department of Orthodontics \\ 2. University of Witwatersrand Department of Orthodontics
}

\begin{abstract}
Objective: Lip position has become one of the most important soft tissue analyses as it influences the occlusion, tooth stability and facial aesthetic. Hence, the objective of this study was to compare the short-term and long-term sagittal lip positions/changes using the Burstone line (B-line). Materials and methods: The sample consisted of 18 Caucasoid females only (14 extractions, 4 non-extractions) who were successfully treated with edgewise appliances. All the patients were evaluated before treatment (T1), at the end of active treatment (T2), and at a long-term followup observation (T3). The mean age at commencement was 13.2 years with the range of 10.5-19 years. The linear distance between the tip of the lips and the B-line were measured.

Results: T1-T2 time intervals showed the upper lip underwent a mean change of $1.272 \mathrm{~mm}$ relative to the B-line (-32.8\%) which was statistically significant. The lower lip showed a mean change of $1.549 \mathrm{~mm}(-22.2 \%)$, but these changes were not statistically significant.

Lip protrusion relative to the B-line continued to reduce during the long term follow up period. The upper lip showed slight changes $(-9.2 \%)$, whereas the lower lip demonstrated greater change $(-53.8 \%)$.

Conclusion: Using B-line, the sagittal soft tissue lip positions were more retrusive on the long-term follow-up records for both extraction and non-extraction cases, their values were not very different from the normal values of the untreated cases. Although the upper lips were retrusive post treatment, the differences were not statistically significant. However, the lower lips retrusion from T1-T2 were found to be statistically significant.
\end{abstract}

Sathekge R., Lesar C. Evaluation of long-term sagittal lip changes using Burstone line: pilot study. South Eur J Orthod Dentofac Res. 2020;7(2)32-37.

\section{INTRODUCTION}

The soft tissue lip analysis is crucial for diagnosis and orthodontic treatment planning. Whether viewed dynamically or statically, individual facial harmony and profile balance are determined by the interaction between the soft tissues themselves, the characteristics of the underlying skeletal foundation and the positions of the teeth. All these factors combine to provide the visual impact of the face. ${ }^{1-3}$ Among the objectives of orthodontic treatment is the achievement of this very balance and harmony between the hard and soft tissues. The ability to predict the final soft tissue drape of the face is

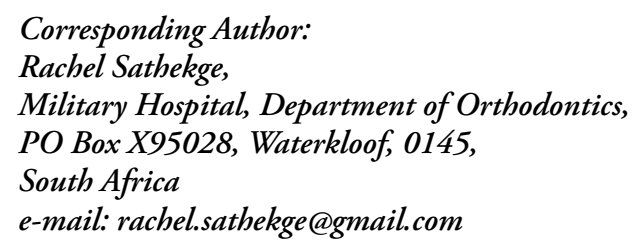

of paramount importance to the orthodontists. Studying the immediate and the long-term effects of treatment on the soft tissues is of concern in clinical orthodontics as these factors could be crucial to the public's perception of the acceptability of orthodontics. Bishara et al found that patients who undergo extractions tend to have straighter faces and slightly more upright maxillary and mandibular incisors, while those treated non-extraction have the opposite tendencies. ${ }^{4,5}$ Other studies also showed that these differences between the two groups were maintained for two years following treatment. ${ }^{6-8}$ More recently, however, a preliminary study of the threedimensional effects of orthodontic treatment on the facial soft tissues by Ismail and Moss found no evidence that the extraction of teeth resulted in a flattening of the facial soft tissue profile. ${ }^{9}$ The soft tissue facial profiles of the extraction and non-extraction samples were similar following active treatment and a long-term post-treatment period of fourteen years. ${ }^{10}$ 
There have been only a few studies which have attempted to assess the long-term soft tissue lip changes induced by treatment. Mostly, these studies used Rickett's-line (E-line) and/or Steiner's-line (S-line) to evaluate the soft tissue changes. ${ }^{11}$ Burstone used a plane, the Burstone line (B-line) connecting subnasale and soft tissue pogonion to evaluate relative protrusion or retrusion of the lips. The $\mathrm{B}$-line is a plane of minimal variation in the area of the face. ${ }^{11,12}$

Hsu found the B-line to be the analytical reference line with the most consistency and sensitivity when used as a reference for lip balance and harmony on the lateral facial profile tracing. ${ }^{13}$ When compared with other analytical reference lines, e.g., Ricketts E-line, the B-line has the smallest coefficient of variation; it provides the narrowest dispersion and the best consistency in terms of judging facial profiles. ${ }^{13}$ Due to the $\mathrm{B}$ line's reliability and consistency which is characterized by the fact that it does not transverse over any anatomical landmarks of the nose and is thus not affected by growth of the nose, as well how it is close to a skeletal structure points to why the B-line is often employed as the reference line of choice in the soft tissue lip changes. Since, soft tissues play the primary role of physical appearance and facial esthetics, it is important to use a method of choice in the soft tissue lip changes, such as B-line.

The balance of facial structures is affected by both orthodontic treatment and growth. Most of the soft tissue growth changes at the nose, lips and chin suggest sexual dimorphism. Males exhibit greater increases, due to growth occurring over a longer time span than in females. Most of the soft tissue measurements in females have attained adult size by age 15 years, whereas in males these are increasing even at 18 years of age. ${ }^{1,2}$ Thus, in a pilot study it may be important to validate the approach by restricting the sample size to females only. These observations would therefore justify a more in depth look at the longterm lip changes in patients where growth can be excluded.

Of all the soft tissues, the lip profile is that which the orthodontist has the most potential to change. Therefore, by concentrating on lip changes and by using a relatively simple diagnostic tool such as the B-line it is hoped that the orthodontist can be aided in the quest for predictable lip changes.

Hence, the study was undertaken to evaluate the lip soft tissue changes occurring in response to tooth movement not only immediately following orthodontic treatment but also to assess the long-term changes.

\section{MATERIALS AND METHODS}

The ethical committee approved the study (M 02-09-33). The cephalometric records of eighteen female patients with availability of good quality pre-treatment (T1), post- treatment (T2) and long-term follow-up (T3) lateral cephalometric radiographs exhibiting a clear soft-tissue profile, and had undergone comprehensive orthodontic treatment with edgewise appliances were included in this study.

The sample included Class I, Class II and Class III malocclusion types. The selected female Caucasian sample of 18 consisted of 14 extraction and 4 non-extraction cases. The mean age at commencement of treatment was 13.2 years with the range of 10.5 - 19 years. Since most of the soft tissue measurements in females have attained adult size by age 15 years, ${ }^{2}$ the sample was restricted to females only as explained in the introduction.

\section{Cephalometric analysis}

Cephalometric radiographs were traced and digitized twice by the same investigator. The error differences in landmark identification for the linear and angular measurements were within $0.63 \mathrm{~mm}$ and 0.71 degrees, respectively. The radiographs were traced utilizing a standard format on Ozatex $0.05 \mathrm{~mm}$ DMN drafting film paper (Ozalid SA Pty Ltd), using a $6 \mathrm{H}$ lead pencil, and the measurements were made employing a Kontron Digital Analyzer (Image-Analysis-Systems, West Germany).

The landmarks included were: - sella turcica, nasion, porion, orbitale, posterior and anterior nasal spine, hard tissue pogonion, menton, gnathion, gonion, A-point, B-point, upper incisor tip and apex, and lower incisor tip and apex, the soft tissue integumental landmarks were drawn according to Burstone, ${ }^{14}$ and the method included: subnasale, labrale superius, labrale inferius and soft tissue pogonion. Point subnasale $(S n)$ was located along a line drawn tangent to the nasal base area and at an angle of $45^{\circ}$ to the palatal plane (ANS - PNS). Practically, this was achieved by using a $45^{\circ}$ set square ruler. The base of the ruler was orientated along the palatal plane and then slid along this plane until the side of the ruler with a $45^{\circ}$ angle was tangential to the nasolabial contour. Sn was located by marking the deepest point of the nasiolabial contour (Figure 1). This method was used in this study to accurately locate subnasale $(\mathrm{Sn})$.

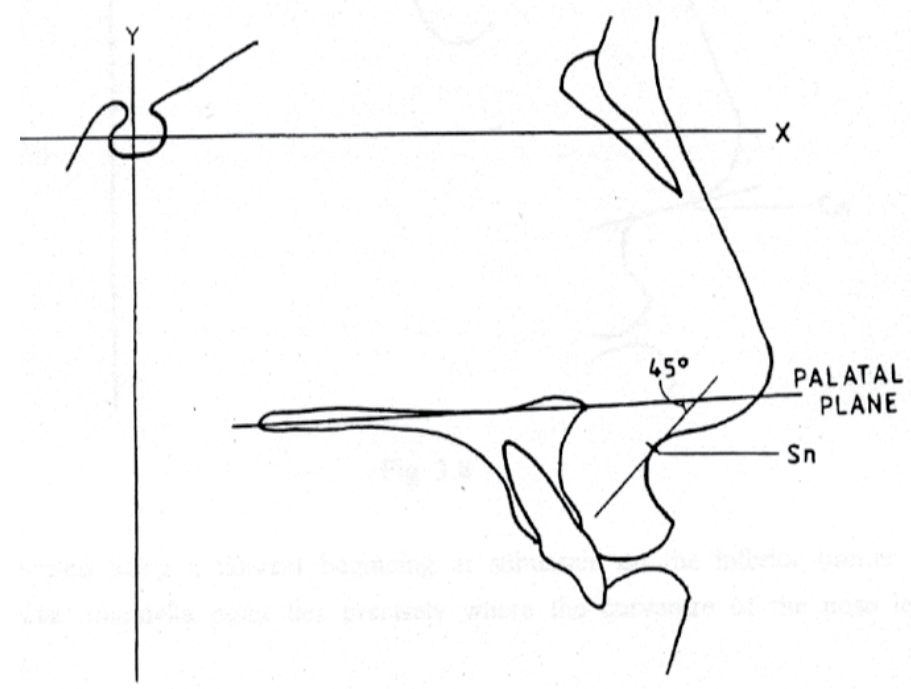

Figure 1. Location of Sn as the deepest of the nasolabial contour. 
Burstone (1967) found that in a "normal" adolescent sample the upper and lower lips were positioned ahead of the subnasalepogonion plane (B-line). On average, the upper lip was 3.5 $\mathrm{mm}(\mathrm{SD}=1.4 \mathrm{~mm})$ anterior to the line and the lower lip 2.2 $\mathrm{mm}(\mathrm{SD}=1.6 \mathrm{~mm})$ anteriorly (Figure $2 \mathrm{a})$.

The hard tissue integumental landmarks were drawn according to Steiner. ${ }^{11,15,16}$

In order to standardize the results, the magnification factor was added to or subtracted from each of the linear measurements measured by the Kontron Digital Analyser. This procedure was applied to all the measurements throughout this study.

\section{Statistical evaluation}

A statistical analysis of the data was conducted using STATA RELEASE 16 Software. This included descriptive and correlative procedures. Means and Standard Deviations, (SD) were calculated for individual data for the pre-treatment (T1), post-treatment (T2) and long-term follow-up (T3) time periods. Considering the small sample size, the paired Student t-test was used to evaluate whether there was any statistically significant difference between the data of the extraction and non-extraction treatment groups at the pre-treatment (T1), post-treatment (T2) and the long-term follow-up treatment (T3) intervals. The level of significance was set at $\mathrm{p}<0.05$. Approval for this study was granted by the Ethics Committee of the University of the Witwatersrand.

\section{RESULTS}

Since the cases chosen for this study included Class I, II, III malocclusions, both the upper and lower lips exhibited a wide range of protrusion or retrusion relative to the B-line before orthodontic treatment. The mean projection of the upper lip pre-treatment (T1) was recorded at $5.05 \mathrm{~mm}(\mathrm{SD}=2.02)$ whereas mean lower lip protrusion was $3.93 \mathrm{~mm}(\mathrm{SD}=2.53)$ (Figure $2 \mathrm{~b}$ ). This relative lip protrusion could be due to upper and lower incisor inclinations that ranged from 9.71 to 32.4 degree when measured to the NA-line (mean $=21.56$ degree) and 10.98 degree to 41.63 degree when measured to the NBline $($ mean $=27.84)$, respectively.

Post-Treatment (T2) measurements for the upper and lower lip to the B-line were within the normal values as described by Burstone (1967). The upper lip to the B-line mean value was $3.79 \mathrm{~mm}(\mathrm{SD}=2)$, although the range varied from $-0.4 \mathrm{~mm}$ to $+7.97 \mathrm{~mm}$. The lower lip to B-line mean value was 2.53 $\mathrm{mm}(\mathrm{SD}=1.93$, with a range of $-0.79 \mathrm{~mm}$ to $7.85 \mathrm{~mm}$. These values reflected the reduction in protrusion that resulted from treatment and maxillary values hardly changed.

On the long-term follow-up (T3) the soft tissue lip measurement showed continuous slight reduction over the long-term followup. Upper lip to B-line mean of $2.89 \mathrm{~mm}(\mathrm{SD}=2.28)$ compared with that of $3.79 \mathrm{~mm}$ at T2. The lower lip mean was $2.02 \mathrm{~mm}$ $(\mathrm{SD}=2.16)$ compared with $2.53 \mathrm{~mm}$ at $\mathrm{T} 2$.
Means, standard deviations and the level of statistical significance for the upper and the lower lip changes at T2-T3 periods tested with both methods, the Student's t-test and the Wilcoxon's test showed no statistically significant difference between the extraction and non-extraction groups, the p-value being greater than 0.1 (Table 1). The non-extraction group showed $0.11 \mathrm{~mm}$ and -0.05 $\mathrm{mm}$ mean changes for upper and lower lip respectively (Table 1 ).

Table 1. Means, SD and level of significance for upper and lower lip changes

\begin{tabular}{|c|c|c|c|c|}
\hline Variables & $\begin{array}{l}\text { Mean and SD } \\
\text { Extraction }\end{array}$ & $\begin{array}{l}\text { Mean and SD } \\
\text { Non-Extraction }\end{array}$ & $\begin{array}{l}\text { t-test } \\
\text { Two-sample }\end{array}$ & $\begin{array}{l}\text { Wilcoxon test } \\
\text { Two-sample }\end{array}$ \\
\hline $\begin{array}{l}\text { UL to B-line } \\
(\mathrm{mm}) \mathrm{T} 2-\mathrm{T} 3\end{array}$ & $\begin{array}{l}0.875 \text { (Mean) } \\
1.172 \text { (SD) }\end{array}$ & $\begin{array}{l}0.105 \text { (Mean) } \\
0.948 \text { (SD) }\end{array}$ & $\mathrm{p}=0.249$ & $\mathrm{p}=0.243$ \\
\hline $\begin{array}{l}\text { LL to B-line } \\
(\mathrm{mm}) \mathrm{T} 2-\mathrm{T} 3\end{array}$ & $\begin{array}{l}0.364 \text { (Mean) } \\
1.077 \text { (SD) }\end{array}$ & $\begin{array}{l}-0.047 \text { (Mean) } \\
1.168 \text { (SD) }\end{array}$ & $\mathrm{p}=0.516$ & $\mathrm{p}=0.915$ \\
\hline
\end{tabular}

$U L=$ Upper lip, $L L=$ Lower lip, $B$-line $=$ Burstone line, $T 2=$ post-treatment,$T 3=$ the long-term follow-up treatment

The post-treatment values in almost all the variables, skeletal, dental or soft tissues, were close to normal values. In general, the long-term follow-up cases demonstrated minimal change or no change at all in the values that were recorded post-treatment (T2) and also with reference to the norms.

Changes during treatment (T1-T2), the upper lip underwent a mean change of $1.272 \mathrm{~mm}$ relative to the B-line $(-32.8 \%)$ (Figure 2c) which was statistically significant. The lower lip showed a mean change of $1.549 \mathrm{~mm}(-22.2 \%)$, but these changes were not statistically significant (Table 2).

Changes during follow-up (T2-T3), the upper lip showed slight changes $(-9.2 \%)$, whereas the lower lip demonstrated greater change $(-53.8 \%)$ (Figure $2 \mathrm{~d}$ ). Although the mean percentage changes recorded for T2-T3, for both lips were relatively large, they were not statistically significant (Table 3). Therefore, a separate consideration of composite changes that occurred from T1 to T3, was deemed not necessary.

The soft tissue integument for both upper and lower lips changed markedly from pre-treatment (T1) to the long-term follow-up (T3). Both lips underwent reduction in protrusion; more during treatment and to a lesser extent during the long-term followup. However, these changes were not statistically significant. The hard tissues followed a similar pattern.

It was found from the observed changes that upper lip change depended on the lower lip only and the relationship was shown by using backward stepwise regression analysis with a coefficient of determination (R2) of $29 \%$.

From these observations it can be concluded that lip changes over the long-term follow-up period revealed no significant changes. The lips remained, relatively, in the same position that they had attained immediately after treatment. This was the case for both the extraction and non-extraction cases. 


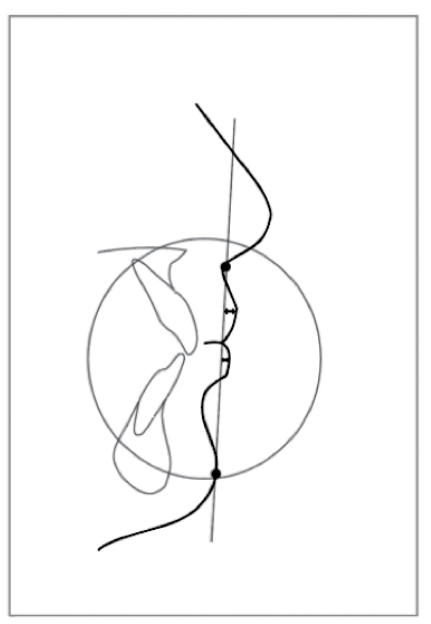

A

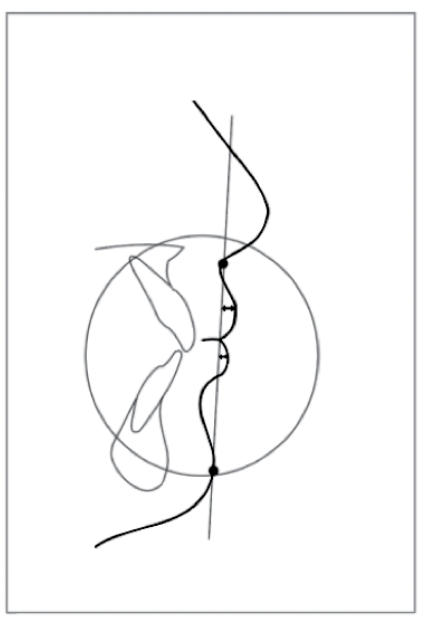

C

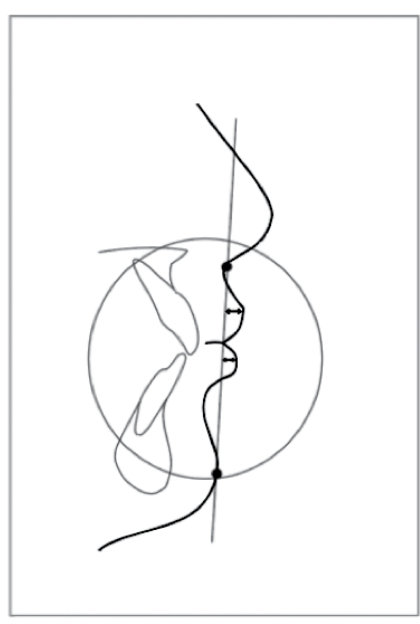

B

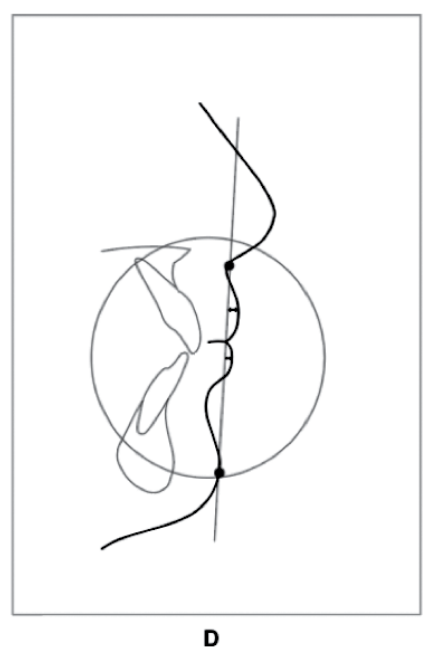

D
Figure 2. (A) On average the normal measurements are; the upper lip $=3.5 \mathrm{~mm}$ $(S D=1.4 \mathrm{~mm})$ and the lower lip $=2.2 \mathrm{~mm}(S D=1.6 \mathrm{~mm})$ to $B$-line.

(B) Pre-treatment (T1) lip protrusion measurements were; the upper lip $=5.05 \mathrm{~mm}$ $(S D=2.02)$ and lower lip $=3.93 \mathrm{~mm}(S D=2.53)$.

(C) Post-treatment (T2) measurements were; the upper lip $=3.79 \mathrm{~mm}(S D=2)$ and the lower lip $=2.53 \mathrm{~mm}(S D=1.93)$.

(D) Long-term follow-up (T3) measurements were; Upper lip $=2.89 \mathrm{~mm}$ $(S D=2.28)$ and the lower lip was $2.02 \mathrm{~mm}(S D=2.16)$.

\section{DISCUSSION}

This study was undertaken to evaluate the short-term and long-term sagittal soft tissue lip changes occurring following orthodontic treatment using the B-line. Despite a large number of studies on the short- and long-term effects of orthodontic treatment on patient's facial soft tissue, the accomplishment of soft-tissue profile changes by dental movement is limited but has a significant role in improving the esthetic of facial soft tissue. ${ }^{10,17}$ The results of this study support the reported progressive flattening of the facial profile in both groups in both extraction and non-extraction groups, by demonstrating retrusion of the lower lip on long term follow-up. Importantly our findings using a B-line are also concurs with the results of other studies that were carried out with other cephalometric soft tissue analyses. ${ }^{18-22}$ Our study further shows that on a shortterm follow-up there is a reduction in protrusion of the upper lip.

This pilot work emboldens the fact that pre-treatment and long term follow up comparisons (T1-T3) between groups should provide the clinician with some insight as to the criteria on which the extraction or non-extraction decision was based.

Post-treatment comparisons (T2-T3) are useful in determining variances of the soft tissue between the extraction and nonextraction groups after completion of the orthodontic and orthopaedic treatment. It should be emphasized that such direct comparisons do not determine, per se, whether one group looks better than the other. The facial profiles were similar in both groups, since all individuals with and without extraction were initially diagnosed to solve the tooth size discrepancy with the options of either extraction or no-extraction.

Measurements and clinical observations of soft tissues require careful attention because of individual variations in soft tissue thickness and regional independence of the underlying skeleton, hence the choice of B-line in this study. Changes in profile appear to be related to variables such as pre-treatment lip strain, variations in lip structure and thickness, and the extent of incisor retraction. It is important that the orthodontist be conscious of changes brought about by late adolescent and post-pubertal growth. Various studies have detailed the changes that take place in the soft tissues in the period from childhood to adulthood. Bishara, et al, found that in untreated cases the upper and lower lips become markedly more retruded in relation to the E-line between 15 and 25 years in males and 10 and 15 years in females. ${ }^{17,23}$ This trend continued between 25 and 45 years of age in both males and females for the upper lip, but at a much smaller magnitude. Between 25 and 45 years, the lower lip became more protrusive in males but slightly more retrusive in female. This was also observed in the current study. In this study a mean difference of $1.4 \mathrm{~mm}$ for the upper lip to the B-line and $2.0 \mathrm{~mm}$ for the lower lip to the B line was observed in the extraction group. The mean linear changes in these variables were very similar to those noted in the other studies albeit at a slightly lower value. ${ }^{23}$

The use of the $\mathrm{E}$ line to assess profile aesthetics is often criticized because it is excessively influenced by the size of the nose and its remaining growth. In this study, the upper and lower lips as measured to the B-line moved slightly back after treatment in the extraction group when compared with the non-extraction group as shown in Table 1. Additionally, as demonstrated in Table 3, the pooled data showed continued reduction in both upper and lower lip protrusion on the long-term follow-up.

After successful completion of treatment, comparison between extraction and non-extraction groups revealed no differences in 
any measures of soft tissue profile. Following an average posttreatment period of approximately ten years, group comparison also revealed no differences in profile measurements. However, the lips were retruded relative to the B-line. In the present study, the mean changes that occurred from post-treatment to long term follow-up were not statistically significant.

The facial profiles of extraction and non-extraction groups were the same following treatment and long-term post-treatment. However, there was a slight tendency for the profile to flatten despite the fact that the patients had stopped growing as mentioned above. These results are also in accordance with several studies that found similar morphology of hard, dental and soft tissue profiles in their comparison of extraction and non-extraction groups approximately fourteen years posttreatment. ${ }^{18-22}$

\section{Limitations of the study}

The following are limitations to our study. First, this study utilized a small sample size. Second, the gender differentiation was not done. Hence, making it difficult to find detailed information regarding each subject when doing retrospective study especially over a long period of 10 years. The changes in the upper lip in response to orthodontic tooth movement (T2) were predictable in this study using a simple reliable B-line. Lower lip response to orthodontic treatment were more noticeable at T3, concurring with the presently available cephalometric techniques. The pendulum in treatment decisions over the past number of years swung decidedly towards the non-extraction treatment modalities, ${ }^{24,25}$ however our pilot study results do not demonstrate any preference between extraction and the nonextraction treatment modalities.

Future studies in this area should explore a more extended follow-up interval between the completion of treatment and retention to differentiate malocclusion and comparing different cephalometric soft tissue analysis.

\section{CONCLUSION}

Our study of lateral cephalometric records using B-line, shows that the sagittal soft tissue lip positions were more retrusive on the long-term follow-up records for both extraction and non-extraction cases, their values were not very different from the normal values of the untreated cases. Although the upper lips were retrusive post treatment, the differences were not statistically significant. However, the lower lips retrusion from T1-T2 were found to be statistically significant.

\section{CONFLICT OF INTEREST}

The authors of the present article declare no conflicts of interest.
Table 2. Changes effected during treatment (T1 - T2)

\begin{tabular}{lllll}
\hline & Mean & SD & Mean change \% & p-value \\
\hline SKELETAL & & & & \\
\hline ANB $\left(^{\circ}\right)$ & 1.187 & 0.887 & $0.7 \%$ & 0.9785 \\
\hline Wits $(\mathrm{mm})$ & 0.655 & 0.967 & $-57.9 \%$ & 0.1354 \\
\hline Y-axis $\left(^{\circ}\right)$ & -1.12 & 1.325 & ${ }^{*} 1.6 \%$ & 0.0037 \\
\hline Mand plane $\left(^{\circ}\right)$ & -0.622 & 2.021 & $1.9 \%$ & 0.2059 \\
\hline A-N - FH $(\mathrm{mm})$ & 0.929 & 1.405 & $-34.2 \%$ & 0.3255 \\
\hline Po-NB $(\mathrm{mm})$ & -0.622 & 0.904 & $34.7 \%$ & 0.1342 \\
\hline DENTAL & & & & \\
\hline UI to NA $\left(^{\circ}\right)$ & 2.147 & 8.304 & $-4 \%$ & 0.6772 \\
\hline UI to NA (mm) & 1.506 & 1.584 & $*-23.4 \%$ & 0.029 \\
\hline LI to NB $\left(^{\circ}\right)$ & 2.4 & 5.426 & $-3.5 \%$ & 0.5972 \\
\hline LI to NB $(\mathrm{mm})$ & 0.731 & 1.524 & $-4 \%$ & 0.6069 \\
\hline LI to APo $(\mathrm{mm})$ & 0.562 & 2.370 & $-51.8 \%$ & 0.1783 \\
\hline SOFT TISSUE & & & & \\
\hline UL to B-line $(\mathrm{mm})$ & 1.272 & 1.088 & $*-32.8$ & 0.037 \\
\hline LL to B-line $(\mathrm{mm})$ & 1.549 & 1.426 & $-22.2 \%$ & 0.2254 \\
\hline
\end{tabular}

$A-N \perp F H=$ Point $-A$ to Nasion perpendicular to Frankfort Horizontal, $P o=$ Pogonion, $N B=$ Nasion to Point $-B, N A=$ Nasion to Point $-A, U I=$ Upper incisor, $L I=$ Lower incisor, Apo $=$ Point-A to Po, UL $=$ Upper lip, $L L=$ Lower lip, B-line $=$ Burstone line \# Marginally Significant: $0.05>p<0.1$

* Significant: $p<0.05$

Table 3. Mean changes effected during the long-term follow-up (T2 - T3)

\begin{tabular}{lllll}
\hline & Mean & SD & Mean change $\%$ & p-value \\
\hline SKELETAL & & & & \\
\hline ANB $\left(^{\circ}\right)$ & 0.304 & 1.04 & $\#-29.5 \%$ & 0.0885 \\
\hline Wits $(\mathrm{mm})$ & -0.097 & 1.472 & $0.8 \%$ & 0.9733 \\
\hline Y-axis $\left(^{\circ}\right)$ & 0.596 & 1.887 & $-0.9 \%$ & 0.1930 \\
\hline Mand plane $\left(^{\circ}\right)$ & 1.783 & 2.193 & $\#-11 \%$ & 0.0601 \\
\hline A-N-FH $(\mathrm{mm})$ & 0.599 & 1.707 & $33.5 \%$ & 0.5755 \\
\hline Po-NB $(\mathrm{mm})$ & -0.442 & 0.45 & $\# 12.1 \%$ & 0.0538 \\
\hline DENTAL & & & & \\
\hline UI to NA $\left(^{\circ}\right)$ & 0.006 & 6.013 & $6.1 \%$ & 0.4740 \\
\hline UI to NA $(\mathrm{mm})$ & -0.704 & 1.813 & $* 30.6 \%$ & 0.0261 \\
\hline LI to NB $\left(^{\circ}\right)$ & 0.136 & 4.558 & $0.2 \%$ & 0.9748 \\
\hline LI to NB $(\mathrm{mm})$ & -0.075 & 1.266 & $1.4 \%$ & 0.8337 \\
\hline LI to APo $(\mathrm{mm})$ & -0.39 & 1.753 & $-30.6 \%$ & 0.5670 \\
\hline SOFT TISSUE & & & & \\
\hline UL to B-line $(\mathrm{mm})$ & 0.704 & 1.148 & $-9.2 \%$ & 0.5736 \\
\hline LL to B-line $(\mathrm{mm})$ & 0.273 & 1.077 & $-53.8 \%$ & 0.1217 \\
\hline
\end{tabular}

$A-N \perp F H=$ Point $-A$ to Nasion perpendicular to Frankfort Horizontal, $P o=$ Pogonion, $N B=$ Nasion to Point $-B, N A=$ Nasion to Point $-A, U I=$ Upper incisor, $L I=$ Lower incisor, Apo $=$ Point $-A$ to Po, $U L=$ Upper lip, $L L=$ Lower lip, $B$-line $=$ Burstone line \# Marginally Significant: $0.05>p<0.1$

* Significant: $p<0.05$ 


\section{REFERENCES}

1. Turley PK. Evolution of esthetic considerations in orthodontics. Am J Orthod Dentofacial Orthop. 2015;148: 374-9.

2. Nanda RS, Ghosh J. Facial soft tissue harmony and growth in orthodontic treatment. Seminars in Orthodontics. 1995;1: 67-81.

3. Kingsley NA. A treatise on Oral Deformities: As a Branch of Mechanical Surgery. England HK Lewis, 2017.

4. Bishara SE, Cummins DM, Zacher AR. Treatment and post-treatment changes in patients with Class II Div 1 malocclusion after extraction and non-extraction treatment. Am J Orthod Dentofacial Orthop. 1997;111: 18-27.

5. Janson G, Castello Branco N, Aliaga-Del Castillo A, Henriques JFC, de Morais JF. Soft tissue treatment changes with fixed functional appliances and with maxillary premolar extraction in Class II division 1 malocclusion patients. Eur J Orthod. 2018;40: 214-22.

6. Evrard A, Tepedino M, Cattaneo PM, Cornelis MA. Which factors influence orthodontists in their decision to extract? A questionnaire surveys. J Clin Exp Dent 2019;11: 432-438. [PMID: 31275515].

7. Paquette DE, Beattie JR, Johnson LE Jr. A long-term comparison of non-extraction and premolar extraction edgewise therapy in "borderline" Class II patients. Am J Orthod. 1992; 102: 1-14.

8. Luppanapornlarp $S$, Johnston LE Jr. The effects of premolar-extraction: A longterm comparison of outcomes in "clear-cut" extraction and non-extraction Class II patients. Angle Orthod. 1993; 63: 257-72.

9. Ismail SFH, Moss JP. The three-dimensional effects of orthodontic treatment on the facial soft tissues - a preliminary study. Br Dent J. 2001;192: 104-8.

10. Zierhut EC, Jooneph DR, Artun J, Little RM. Long term profile changes associated with successfully treated extraction and non-extraction Class II Div 1 malocclusions. Angle Orthod. 2000; 70: 208-19.

11. Burstone CJ. Lip posture and its significance in treatment planning. Am J Orthod. 1967; 53: 262-84.

12. Maddalone M, Losi F, Rota E, Baldoni MG. Relationship between the Position of the Incisors and the Thickness of the Soft Tissues in the Upper Jaw: Cephalometric Evaluation. Int J Clin Pediatr Dent. 2019;12: 391-7.
13. Hsu BS. Comparison of the five analytic reference lines of horizontal lip position: their consistency and sensitivity. Am J Orthod Dentofacial Orthop. 1993; 104: 355-60.

14. Burstone CJ. The integumental profile. Am J Orthod. 1958; 44: 1-25.

15. Steiner CC. Cephalometrics for you and me. Am J Orthod. 1953; 39:729-755.

16. Kailasam V, Valiathan A. Cephalometrics for you and me-Valid in today's scenario? J Indian Orthod Soc. 2018;52: 101-4.

17. Bishara SE, Jakobsen JR, Hession TJ, Treder JE. Soft tissue profile changes from 45 years of age. Am J Orthod Dentofacial Orthop. 1998; 114: 698-706.

18. Battagel JM. Profile changes following treatment of Class II Div 1 malocclusion: a comparison of the effects of Edgewise and Frankel appliance techniques. Eur J Orthod. 1989;11: 243-53 [PMID: 2792214].

19. Drobocky OB, Smith RJ. Changes in facial profile during orthodontic treatment with extraction of four first premolars. Am J Orthod Dentofacial Orthop. 1989; 95: 220-30.

20. Freitas BV, Rodrigues VP, Rodrigues MF, de Melo HVF, Dos Santos PCF. Soft tissue facial profile changes after orthodontic treatment with or without tooth extractions in Class I malocclusion patients: A comparative study. J Oral Biol Craniofac Res. 2019; 92: 172-6.

21. Bravo, L.A. Soft tissue facial profile changes after orthodontic treatment with four premolars extracted. Angle Orthod. 1994; 64: 31-42.

22. Maetevorakul S, Viteporn S. Factors influencing soft tissue profile changes following orthodontic treatment in patients with Class II Division 1 malocclusion. Prog Orthod. 2016; 17:13.

23. Janson G, Aliaga-Del Castillo A, Niederberger A. Changes in apical base sagittal relationship in Class II malocclusion treatment with and without premolar extractions: A systematic review and meta-analysis. Angle Orthod. 2017;87: 338-355.

24. Finnoy JP, Wisth PJ, Boe OE. Changes in soft tissue profile during and after orthodontic treatment. Eur J Orthod. 1987; 9: 68-78.

25. Almurtadha RH, Alhammadi MS, Fayed MMS, Abou-El-Ezz A, Halboub E. Changes in Soft Tissue Profile After Orthodontic Treatment With and Without Extraction: A Systematic Review and Meta-analysis. J Evid Based Dent Pract. 2018;183: 193-202. 